\title{
Ameliorative Study of a Scramjet Engine by Regenerative Cooing using Finite Element
}

\author{
Ansh Verma
}

\begin{abstract}
It took man thousands of year to go from a wheel to a car, but only a decade to reach into the space. Keeping in mind this pace of development, this theory based research paper discuss the recent technology in air-breathing engines : The Scramjet Engine.

Scramjet Engines are supersonic Air-Breathing Aeroengines that propels the host aerostructure to supersonic speeds greater than Mach 7. The current field of scramjet propulsion is facing metallurgical issues as the scramjet combustion-chamber's heat load is so large that even the most advanced composite materials are not able to withstand it. At the peak value of supersonic air intake in the engine, the air entering is at extreme temperature thus unfit for cooling the structure. Thus a regenerative cooling cycle is being proposed to thermodynamically optimize the scramjet system, using the fuel (which is liquid hydrogen) as the primary coolant.

Liquid Hydrogen, the fuel used for scramjet combustion has an enthalpy of combustion of $286 \mathrm{~kJ}^{\mathrm{m}} \mathrm{mol}^{-1}$ with a specific heat

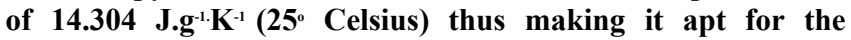
combustion as well as cooling purpose respectively.The Regenerative cycle proposed for the cooling system is different from the conventional.The circulation of Hydrogen is done twice thereby increasing the fuel heat sink. Thermodynamical analysis were done and the comparisons of the two states were also obtained giving a result of increment of $35 \%$ on the overall efficiency.
\end{abstract}

\section{INTRODUCTION}

The field of Scramjet Engine has attracted many researchers form all over the world since it was first technically proposed in 1973, by William J. Small, John P. Weldner and P.J.Johnston at Langley Research Centre NASA, Virginia. The parent concept of Scramjet, The Ramjet Engine, dates backs to 1913 when the French inventor René Lorin, proposed the idea of a ramjet cannonball. Since then many have worked on the development of a system which is able to break the sound barrier and hence be used commercially. The fastest aircraft propelled by an air-breathing engine is the SR-71 Blackbird that reaches up-to a speed slightly over mach 3.The big potential of scramjet engine lies in the propulsion of missile system, Hypersonic aircrafts and launch vehicles.

Successful attempts have been made in the practical implementation of the scramjet technology. The most successful one being done by NASA with their X-43A project. The $\mathrm{X}-43 \mathrm{~A}$ is a single use vehicle designed to crash into the ocean without recovery. Two of them flew successfully, with the scramjet operating for approximately 10 seconds, followed by a 10 minute glide and then the intentional crash.In India the scramjet program is done by
ISRO (VSSC) and DRDO. The name of the project is AVATAR which is abbreviated for Aerobic Vehicle for Hypersonic Transportation.

The usage of scramjet engine has proved to be quiet beneficial in both financial as well as technical terms. As discussed in the following article the amount of moving parts in a scramjet is almost nil. This aero-engine does not have any turbine or compressor or shafts. Thus it is mechanically the simplest of the jet engine power-plants. As defined, it is an air breathing engine. Thus the complexity decreases in the manufacturing point of view.Talking financially, since less number of parts lesser the cost of the assembly. The only expenditure to be incurred in such a technology is in the field of research and development. As we can understand, at high mach speeds of 7-8 the science of laminar flow, shock wave's heating and need for cooling increases.Hence a detailed and strong modeling analysis should be done for the actual prototype to be executed. This is followed by an extensive list of calculation that are needed to be performed.

The major areas of research in the scramjet are the thermal covering of the structure, flame stabilization, aero structure integration, take off and landing of the vehicle. New materials offer good insulation at high temperature, but they often sacrifice themselves in the process. Therefore studies often plan on "active cooling", where coolant circulating throughout the vehicle skin prevents it form disintegrating. Often the coolant is the fuel itself, in much the same way that modern rockets use their own fuel and oxidizer as coolant for their engines. All cooling systems add weight and complexity to a launch system and reduce its efficiency. The increased cooling requirements of scramjet engines result in lower efficiency.

This paper covers the ground of an effective cooling system recently developed in the field of scramjet engine. This system ensures the cooling of the aero-structure as well as provide an auxiliary unit for power generation.

\section{SCRAMJET ENGINE}

A Scramjet Engine is a air-breathing supersonic propulsion unit. It is derived form a Ramjet Engine, as abbreviated to "Supersonic Combustion Ramjet Engine". It is different form the normal turbine jet engines as it has no mechanical unit to compress the air and for the exhaust to occur. The basic parts of a scramjet engine are - Inlet, Isolator, Combustion Chamber, Exhaust Nozzle, fuel supply and cooling subsystems. 


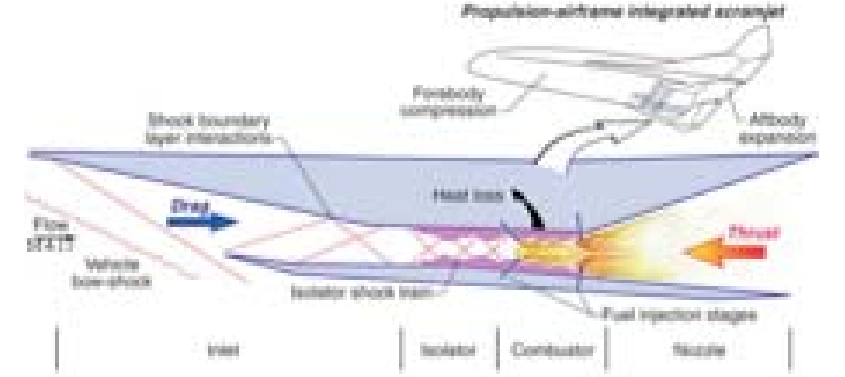

Schematic Representation of the Scramjet Engine(Courtesy: LaRC, NASA)

\section{A. Inlet}

As depicted in the above diagram the inlet of the air is at high mach number generally exceeding 4 . The three wedge system followed in the inlet unit of the engine ensure a compression ratio of about 4 at mach 2 . This is an acceptable substitution to the aero-mechanical compressor, thus simplifying the machinery enormously. The compression of air occurs because of the shock wave developed at the cone of the vehicle. Thus the kinetic energy of the air is converted into pressure, which is also known as Ram- Intake.
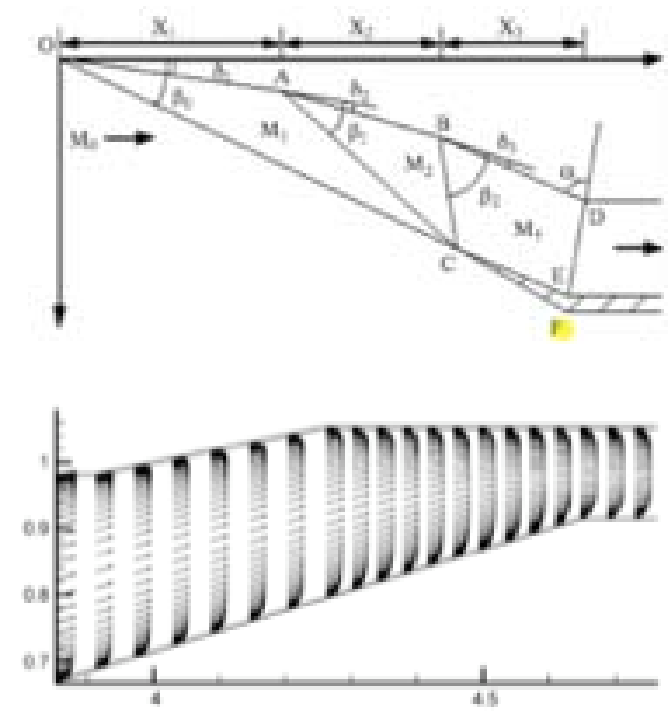

(a)Three wedge Inlet system

(b)Local velocity vectors at inlet

The intake of air happens at a supersonic speed which cannot be allowed for combustion as this flow of air through the duct tends to blow out the combustion. Also at high mach numbers, the shock produces large losses that tends to inhibit the performance of the engine. Thus an Isolator is positioned just after the inlet, before the combustor to slow down the flow through the shock regime, finally producing a subsonic flow in the combustor.

\section{B. Combustor}

After the isolator comes the combustor or the combustion chamber. It is a very integral part of the engine as the chemical reaction of the fuel take place in this chamber. The air entering the chamber is at supersonic speed. A spray of fuel (liquid hydrogen) is introduced in the chamber form the inlet and stops at $1 / 10$ th of the length. Thus the combustion of the fuel starts form that point. The increases in temperature in the combustor increases the local sonic speed of gas reconverting the subsonic flow back to a supersonic exhaust, meaning a higher exit flow velocity.

\section{Exhaust Nozzle}

The entire thrust value of the scramjet engine depends on the design of the exhaust nozzle. The combustion generally occurs at constant area combustion chamber duct at a pressure considerably higher than the ambient pressure. This high pressure is now used to expand the hot air flow form the nozzle, thereby converting a low subsonic flow back to supersonic flow at the exit. The mixture of the air and burned fuel is exhausted through a convergent-divergent (CD) nozzle to the atmosphere at local supersonic jet velocity. Thus the momentum gained by the exiting mass of the exhaust gasses, is reciprocated into thrust of the aerostructure. The thrust force produced is given by:

$$
\begin{gathered}
\mathrm{F}=[\mathrm{m} \operatorname{dot} * \mathrm{~V}] \mathrm{e}-[\mathrm{m} \operatorname{dot} * \mathrm{~V}] \mathrm{o}+(\mathrm{Pe}-\mathrm{Po}) * \mathrm{Ae} \\
\text { where e- exit condition, o- inlet condition. }
\end{gathered}
$$

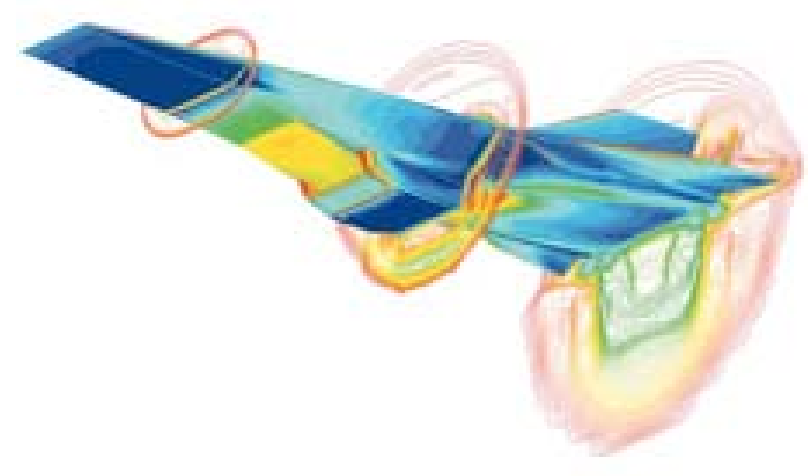

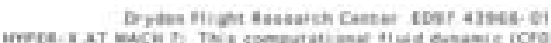

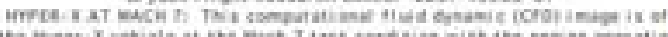

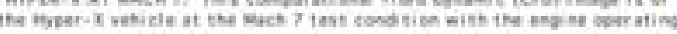

As can be viewed by this CFD model of the working scramjet vehicle of the, we come to realize that the efficiency of the vehicle can be drastically improved if a better cooling system can be devised. The contours in the above analysis depict extremely degree of heat concentrated at the engine structure specially at the combustion chamber. The various other parameter that are to be considered for the heating of this aero-structure are the heating due to boundary layer flow, shock waves developed at the front cone, the combustion of fuel and the exhaust outlet.

The cooling system adopted for the vehicle makes the hydrogen fuel travel across the skin of the combustion chamber once through the ducts, in the mean while getting pre-heated, and is ultimately introduced into the combustion chamber. A better cooling system is proposed recently in which the hydrogen fuel is made to go over the combustion chamber twice before getting combusted. This increases the efficiency of the engine as the thrust value of the engine goes up.

\section{THE REGENERATIVE RE-COOLING SYSTEM}

The present cooling system in the scramjet engine, hydrogen enters the cooling passages as a liquid above the critical pressure $\left(\mathrm{P}_{\mathrm{cr}}=1.3 \mathrm{MPa}\right)$ and at temperature as low as $25 \mathrm{~K}\left(\mathrm{~T}_{\mathrm{fi}}\right)$, which is well below the critical 
temperature $\left(\mathrm{T}_{\mathrm{cr}}=33 \mathrm{~K}\right)$. As the hydrogen continuously flows through the channels, it is quickly heated to above the critical temperature, where it becomes a supercritical gas.

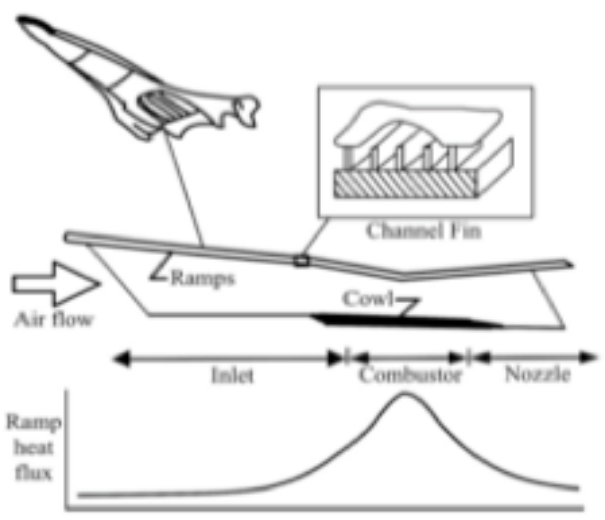

Schematic view of a scramjet with the typical heat fluxes

The diagram depicts a very conceptual Design of a scramjet engine. The basic concentration of heat fluxes can be seen in the graph below it. The inlet and the exhaust have the minimum amount of heat flux, whereas the combustion chamber has the maximum heat flux as the fuel combustion occurs at that place. A typical Ramp heat fluxes varies form 2 to $20 \mathrm{MW} / \mathrm{m}^{2}$. These ramps, typically are equipped with cooling jackets which allows the flow of liquid hydrogen to occur. Since the cooling channels are on the ramps of the combustion chamber the heat exchange takes place immediately. The following is the conventional heating channel schematic diagram.

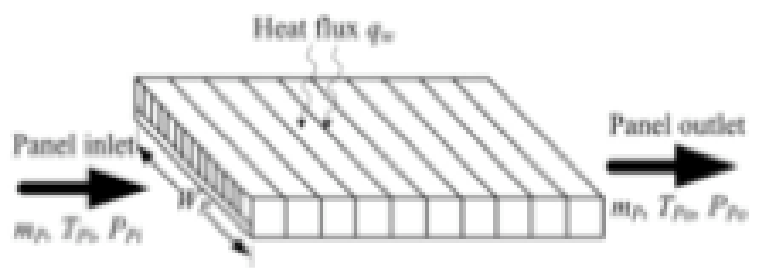

Schematic Diagram of a section of Cooling Channels in Scramjet

The problem with this cooling unit the flow rate of coolant exceeds the stoichiometric flow rate during the flight at a speed above a certain mach number.This implies the fuel heat sink is insufficient, thus more fuel is required on board during the flight and excess fuel has to be abandoned. Also for a conventional aero-engine, flowing air is at a lower temperature. Thus it acts as a cooling agent and it is regarded as infinite. But as the coolant of the scramjet the amount of fuel is limited hence finite. That is why the total cooling capacity does not meet the cooling requirement.

Thus the way out of this problem is to improve the fuel heat sink of Hydrogen. One of the methods is developing an endothermic fuel. This method has proved to be extremely effective in increasing hydrocarbon fuel's chemical heat sink. But in hydrogen fuel it is considered impossible for endothermic catalytic conversions to take place. There are other methods which can increase the fuel heat sink but the price and cost of development for them are relatively high. Moreover attention to combustion characteristics and the introduction of choking, such issues needs to be resolved.

One of the new methods of increasing the fuel heat sink is the Re-cooled Cycle, a possible alternative to the effective use of limited resources available to reduce the fuel flow for cooling. The Re-cooled cycle is a new thermodynamical cycle to solve the status that low-temperature heat source is not sufficient, and the heat capacity of low-temperature heat source is greatly improved by this thermodynamical cycle. This cycle has an excellent potential performance over the conventional cooling system for the vehicle. For a conventional regeneratively cooled scramjet, all the heat obtained directly form the regenerative cooling is taken away by the fuel.The upper limit of temperature in the heat exchange process is thus fixed. If the fuel temperature were below the upper limit then a part of this heat can be converted in to other form of energy, thus the fuel can be used for secondary or multiple cooling cycles. Fuel heat sink can be repeatedly be used to absorb more heat and which is an indirect method of increasing the heat sink per unit of fuel.

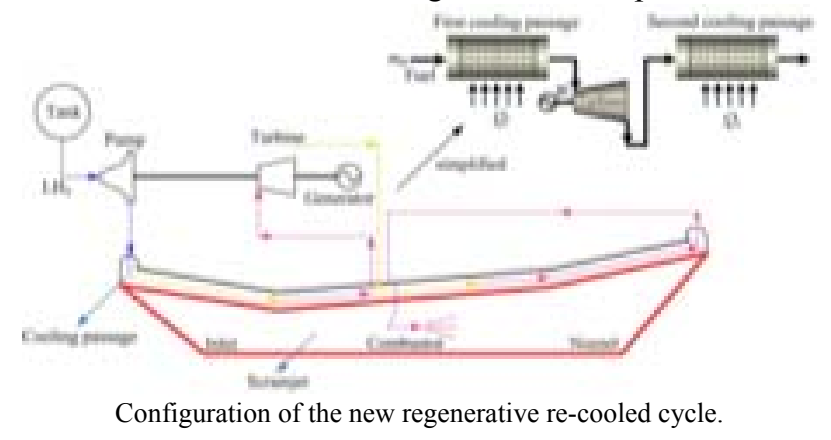

The above schematic diagram shows the new regenerative re-cooled cycle for the scramjet engine. As shown in figure the cycle is mainly composed of the first and second cooling passage, a pump and a turbine. Unlike traditional turbines this turbine is designed to primarily decrease the temperature of the incoming fuel instead of generating work. The dashed lines in the figure show the path taken by the fuel before being injected.

First the fuel coming out of the fuel tank enters into the pump. Here it is pumped to the supercritical pressure, from where it enters into the first cooling passage to cool the heated surface. The temperature of the fuel reaches its highest mark and thus it is introduced to the turbine. The high temperature and high pressure fuel expands in the turbine thereby doing work to the turbine and eventually its temperature decreases. Now it goes to the second cooling duct, absorbs the heat energy thus getting pre-heated and finally gets injected into the combustion chamber. Compared to traditional regenerative cycle the heat absorption per unit of fuel increases for this cycle. Hence the fuel heat sink also increases.

This is beneficial in two ways. Not only the heat sink of the fuel increasing but also we are developing an auxiliary power unit. The turbine's work can be used to power the pump or generate electricity. This can power the vehicles other sub-systems like the radar, communication systems, mechanical control actuation units of the aero-structure, the electrical units e.t.c. Thus a thermodynamic power system consisting of a turbine and an electric generator can partially replace the power supply system of the vehicle. Thus making this unit a multifunctional one. It is something similar to the KERS system used in Formula 1 cars. Using the generated energy of the vehicle to produce energy onboard and hence power other corresponding units of the vehicle. 


\section{CyCle ANALysis}

The analysis begins with classical, ideal, closed-cycle thermodynamic analysis because it contains all of the necessary elements, also the limit considerations.

\section{A. Cycle Description}

The working of a scramjet engine is based on the JouleBrayton thermodynamic cycle. The following representation depicts the thermodynamical cycle.

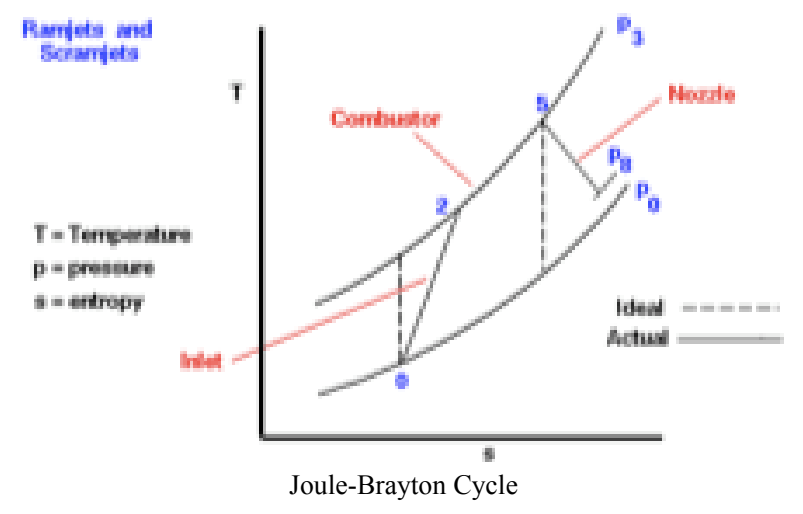

After applying the regenerative re-cooled cycle the following will be the outcome graph

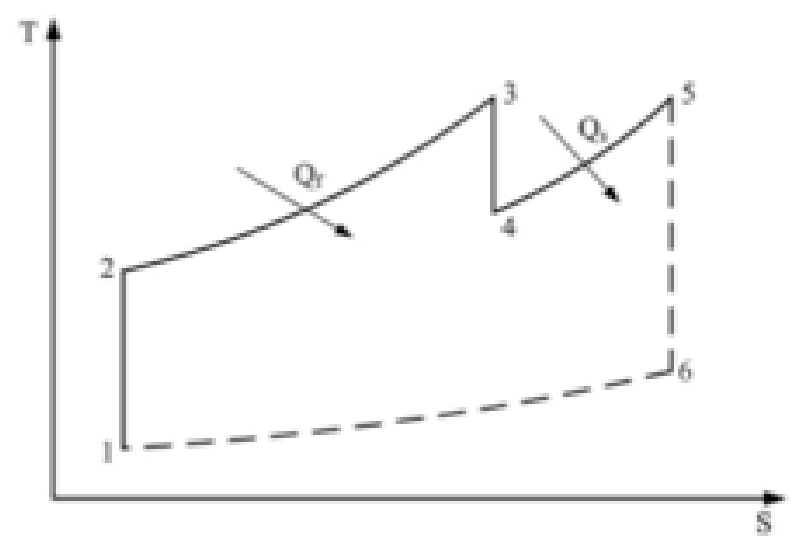

T-S diagram of fuel for the Regenerative Re-Cooled Cycle

The basic working process, wherein $1-2$ is the compression process through the pump, 2-3 the first cooling, 3-4 the expansion through the turbine, 4-5 the secondary cooling. Part 5-6 and 6-1 are assumed outside the engine. $\mathrm{Q}_{\mathrm{f}}$ representing the first cooling heat exchange and $\mathrm{Q}_{\text {s }}$ representing the second cooling heat exchange.

\section{THERMODYNAMICAL FORMULATION}

\section{A. Turbine And Pump}

For pump, the flow rate of turbine is the same with that of pump, so we only concern the specific power of it, which can be estimated as:

$$
\mathrm{W}_{\mathrm{p}}=\left(\mathrm{P}_{\mathrm{po}}-\mathrm{P}_{\mathrm{pi}}\right) / \eta_{\mathrm{p}} \rho_{\mathrm{pi}}
$$

Under the assumptions that there is no loss of power because of friction of the mechanical systems, the turbine outlet temperature can be calculated as:

$$
\mathrm{T}_{\mathrm{to}}=\mathrm{T}_{\mathrm{ti}}\left\{1-\eta_{\mathrm{t}}\left[1-\pi^{(1-\gamma) \gamma}\right]\right\}
$$

Specific power rate of the turbine can be calculated by the following equation:

$$
\mathrm{W}_{\mathrm{t}}=\eta_{\mathrm{t}} \mathrm{C}_{\mathrm{p}} \mathrm{T}_{\mathrm{ti}}\left[1-\pi^{(1-\gamma) / \gamma}\right]
$$

\section{B. Cooling Passages}

According to the thermodynamic properties of hydrogen fuel, the amount of heat exchanged between the fuel and the wall in the first and second cooling passages can be respectively expressed as:

$$
\begin{aligned}
& \mathrm{Q}_{\mathrm{f}}=\mathrm{m}_{\mathrm{R}} \mathrm{C}_{\mathrm{p}}\left(\mathrm{T}_{\mathrm{fo}}-\mathrm{T}_{\mathrm{fi}}\right) \\
& \mathrm{Q}_{\mathrm{s}}=\mathrm{m}_{\mathrm{R}} \mathrm{C}_{\mathrm{p}}\left(\mathrm{T}_{\mathrm{so}}-\mathrm{T}_{\mathrm{si}}\right)
\end{aligned}
$$

The constant heat fluxes inside the engine can be equated to these respective values of heat.

$$
\begin{aligned}
& Q_{\mathrm{f}}=\mathrm{q}_{\mathrm{w}} \mathrm{W}_{\mathrm{c}} \mathrm{L}_{\mathrm{f}} \\
& \mathrm{Q}_{\mathrm{s}}=\mathrm{q}_{\mathrm{w}} \mathrm{W}_{\mathrm{c}} \mathrm{L}_{\mathrm{s}}
\end{aligned}
$$

By geometry the length of the panel can be formulated as:

$$
\mathrm{L}_{\mathrm{p}}=\mathrm{L}_{\mathrm{f}}+\mathrm{L}_{\mathrm{s}}
$$

also the value of the mass flow rate for the cooling can be estimated by the following:

$$
\mathrm{m}_{\mathrm{R}}=\rho \mathrm{WW}_{\mathrm{c}} \mathrm{H}
$$

As can be inferred from the above equation, fuel will accelerate down the length os both the cooling passages, i.e. $\mathrm{u}$ will gradually increase, because $\rho$ decreases with the increase of fuel temperature and which continually increases down the length of cooling passage. As pressure loss of flow in the cooling passages is ignored, so the inlet pressure are equal to the outlet pressures of both cooling passages.

\section{Determination of $L_{f}$ and $M_{r}$ And Reduction Ratio.}

Once the heat balances are obtained in the first and second cooling passages, fuel flow for cooling can be estimated as:

$$
\mathrm{m}_{\mathrm{R}}=\left(\mathrm{q}_{\mathrm{w}} \mathrm{W}_{\mathrm{c}} \mathrm{L}_{\mathrm{p}}\right) / \mathrm{C}_{\mathrm{p}}\left[\mathrm{T}_{\mathrm{fo}} \eta_{\mathrm{f}}\left(1-\pi^{(1-1) / \gamma}\right)-\mathrm{T}_{\mathrm{fi}}+\mathrm{T}_{\mathrm{so}}\right]
$$

Once $T_{\mathrm{so}}$ is set for the given cooling passage structures and characteristics parameters of the turbine $m_{R}$ will be finally determined. Then can be obtained as:

$$
\mathrm{L}_{\mathrm{f}}=\mathrm{L}_{\mathrm{p}}\left(\mathrm{T}_{\mathrm{fo}}-\mathrm{T}_{\mathrm{fi}}\right) /\left[\mathrm{T}_{\mathrm{fo}} \eta_{\mathrm{f}}\left(1-\pi^{(1-\gamma / \gamma)}\right)-\mathrm{T}_{\mathrm{fi}}+\mathrm{T}_{\mathrm{so}}\right]
$$

Now the length factor can be determined as:

$$
\mathrm{y}=\mathrm{L}_{\mathrm{f}} / \mathrm{L}_{\mathrm{p}}=\left(\mathrm{T}_{\mathrm{fo}}-\mathrm{T}_{\mathrm{fi}}\right) /\left[\mathrm{T}_{\mathrm{fo}} \eta_{\mathrm{f}}\left(1-\pi^{(1-1) / \gamma}\right)-\mathrm{T}_{\mathrm{fi}}+\mathrm{T}_{\mathrm{so}}\right]
$$

As the length factor is obtained, length allocation between the first and second cooling passages is determined. Once the length allocation between the first and second cooling passages is determined, i.e. the length factor is fixed, the outlet temperature of the second cooling passage can be obtained as:

$$
T_{\mathrm{so}}=\left(\mathrm{T}_{\mathrm{fo}}-\mathrm{T}_{\mathrm{fi}}\right) / \mathrm{y}-\left[\mathrm{T}_{\mathrm{fo}} \eta_{\mathrm{f}}\left(1-\pi^{(1-\gamma) / \mathrm{r}}\right)+\mathrm{T}_{\mathrm{fi}}\right]
$$


If $T_{s o}$ were equal to $T_{\text {fo }}$, i.e. the maximum cooling capacity of hydrogen fuel were fully made use of in both cooling passages and $\mathrm{T}_{\mathrm{fo}}$ is about 40 times bigger than $\mathrm{T}_{\mathrm{fi}}(25 \mathrm{~K})$.

$$
\mathrm{L}_{\mathrm{f}} \approx \mathrm{L}_{\mathrm{p}} / \eta_{\mathrm{f}}\left(1-\pi^{(1-1 \gamma) \gamma}\right)+1
$$

The reduction ratio of fuel flow for cooling $\Phi$ now can be written as:

$$
\Phi=L_{f} / L_{P}=T_{s o}-T_{f o}\left[1-\eta_{1}\left(1-\pi^{(1-\gamma) / \gamma}\right)\right] / T_{\text {so }}-T_{\text {fo }}\left[1-\eta_{1}\left(1-\pi^{(1-\gamma / \gamma}\right)\right]+\left(T_{f o}-T_{f i}\right)
$$

Also the specific net work output can be expressed as:

$$
\mathrm{W}_{\mathrm{net}}=\eta_{\mathrm{i}} \mathrm{C}_{\mathrm{p}} \mathrm{T}_{\mathrm{ti}}\left[1-\pi^{(1-\gamma) / \gamma}\right]-\left[\left(\mathrm{P}_{\mathrm{po}}-\mathrm{P}_{\mathrm{pi}}\right) / \eta_{\mathrm{p}} \rho_{\mathrm{pi}}\right]
$$

\section{ANSYS RESULTS (REFER TO THE LAST PAGES)}

The modeling of the scramjet engine was done in the ANSYS software using the modeling tool. The modeled scramjet engine was constructed keeping in mind the shell like profile of the engine, for the thermal analysis of the engine. The material used specified for the body of scramjet engine was Titanium Polycrystal .

The model was then meshed specifying free meshed with triangular elements.

After applying the boundary conditions and thermal loads on the engine. The result can be viewed in the next page.The two cooling channels as proposed $n$ this paper were then introduced and the graphical results shown. For the Fluent solver purpose, the model of the scramjet engine was done in the Gambit Software and then later meshed defining al the required zones on the model.

\begin{tabular}{|c|c|}
\hline Element & thermal shell \\
\hline specific heat & $930 \mathrm{~J} / \mathrm{kgK}^{\circ}$ \\
\hline density & $4157 \mathrm{~kg} / \mathrm{m}^{3}$ \\
\hline thermal conductivity & $3.46 \mathrm{~W} / \mathrm{mK}$ \\
\hline
\end{tabular}

Then after creating the mesh file of the model the FLUENT solver was applied to solve the super sonic inlet condition. The results with the meshed grid model can be seen in the diagram pages.

\section{RESULTS AND CONCLUSIONS}

The properties of hydrogen are obtained from the National Institute of Standards and Technology [NIST] Chemistry Web-Book. Since scramjet operates in a wide range Mach Number, the source of heating, both external and internal, is a function of heat released in the combustion process and of the flight Mach number of the scramjet. The RCC should meet the cooling requirements of the whole aero-structure at all conditions.In order to have a numerical appreciation of the results, we consider the cycle pressure ratio $(\pi)$ in the range $1-20$ with $\mathrm{P}_{\mathrm{fi}}$ in the range $1-20 \mathrm{MPa}$ and $P_{\mathrm{so}}=1 \mathrm{MPa}$, the turbine efficiency $\eta_{\mathrm{t}}$ in the range $0.8-1$. 00 , and the outlet temperature of the second cooling passage $\mathrm{T}_{\mathrm{so}}$ in the range $800-1000 \mathrm{~K}$, with $\mathrm{q}_{\mathrm{w}}=2 \mathrm{MW} / \mathrm{m}^{2}, \mathrm{Y}=1.4$, $\mathrm{P}_{\mathrm{pi}}=0.24 \mathrm{MPa}, \rho_{\mathrm{pi}}=71.411 \mathrm{~kg} / \mathrm{m}^{3}, \eta_{\mathrm{p}}=0.7, \mathrm{~T}=25 \mathrm{~K}$ and $\mathrm{C}_{\mathrm{p}}=$ 14. $65 \mathrm{~kJ} /(\mathrm{kg} \mathrm{K})$.

Thermodynamic Optimization for a re-cooled cycle
(RCC) for the scramjet using reduction ratio of fuel flow for cooling as the objective function and by adopting the expansion ratio and the cooling passage length allocation factor as parameters was investigated in this paper.The solution of the cooling passage length allocation factor can also be determined. It is found that the RCC has a max. reduction ration of $35 \%$ however, considering the actual turbine characteristics, the optimal performance of RCC is obtained when the turbine expansion ratio, and length factor are 5 and 0.77 respectively. The corresponding values can be employed in the design and evaluation of the Re-Cooled System.

\section{DIAGRAMS}

The first four diagrams mentioned in the diagram pages show the ANSYS model and its meshed model with the given mentioned specification in the previous pages.

The first result simply shows the result of temperature intensity on the combustion chamber of the engine without the re-cooled cycle. Where as the second result shows the temperature intensity reduction only after the introduction of one re-cooled cycle.

The second set of diagrams represent the work performed in Gambit and Fluent solver. The first diagram represents the grid of the the model with the inlet velocity (blue) and outlet pressure defined (red).

The next diagram shows the velocity profile over the walls of the scramjet engine. The successive diagrams are that of pressure and skin friction co-efficient contours.

\section{ACKNOWLEDGMENT}

I would like to thank Dr. Nadrajan Pillai of Aerospace Engineering SRM University for contributing time from his extremely busy schedule in helping me understand the concepts and solve this problem. Also he extensively helped me in getting a hold of the CFD software used for this research work.

\section{REFERENCES}

[1] Jet Propulsion by Bhaskhar Roy.

[2] Ajay Kumar, J.Philip Drummond, Charles R.

[3] McClinto -Research in Hypersonic Airbreathing Propulsion at the NASA LaRC. ISABE 2001

[4] Jiang Quin, Weixing Zhou, Wen Bao, Daren Yu- Thermodynamic optimization of a scramjet with Re- cooled cycle. ACTA ASTONAUTICA.

[5] Richard R.Kazmar-Airbreathing Hypersonic Propulsion at Pratt and Whitney.

[6] Charles E.Cockrell, Aaron H. Auslender, R.Wayne Guy, Sharon S.Welch-Technology Roadmap for Dual-mode Scramjet Propulsion to support space- access vision vehicle development. AIAA NASA LaRC.
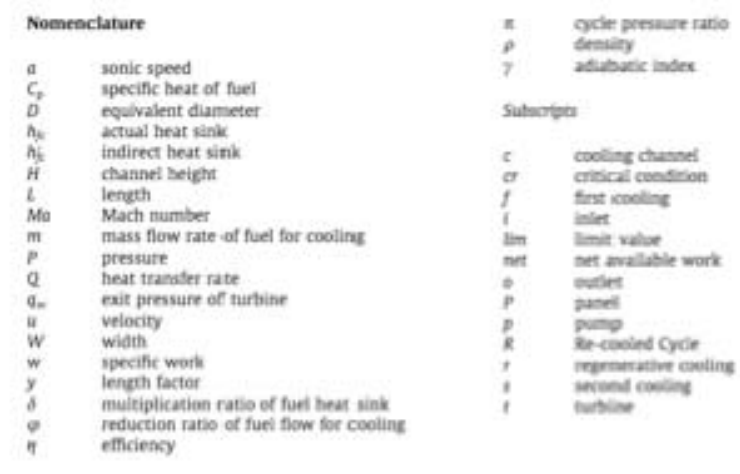
IACSIT International Journal of Engineering and Technology, Vol.2, No.6, December 2010

ISSN: 1793-8236
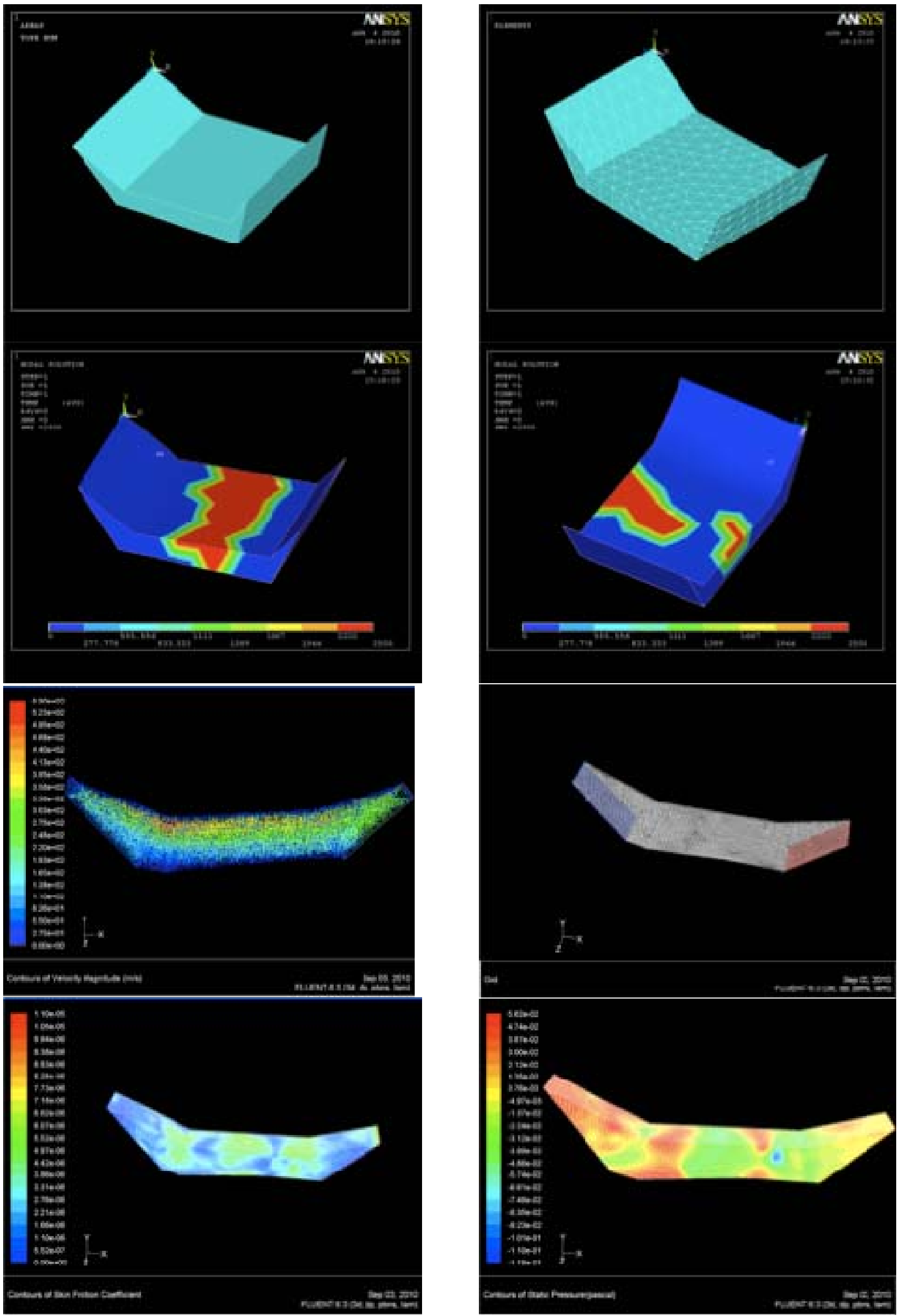